\title{
Studi Penataan pada Tanaman Lanskap Jalan di Bagian Hilir Tukad Mati, Kelurahan Legian, Kecamatan Kuta, Kabupaten Badung
}

\author{
Putu Candra Kusuma Dewi ${ }^{1}$, Ni Wayan Febriana Utami ${ }^{1 *}$, I Gusti Alit Gunadi²
}

1. Prodi Arsitektur Lanskap, Fakultas Pertanian, Universitas Udayana, Jl. P.B. Sudirman, Denpasar, Indonesia

2. Prodi Agroekoteknologi, Fakultas Pertanian, Universitas Udayana, Jl. P.B. Sudirman, Denpasar, Indonesia

*E-mail: wayan_febriana@unud.ac.id

\begin{abstract}
Study Of Structuring Streetscape Plantations At The Tukad Mati Downstream, Legian Village, Kuta District, Badung Regency. This research is motivated by lack of arrangement on streetscape plantations at the downstream of Tukad Mati as well as on-site roblems found such as unfit existing plantations to streetscape planting standar and unsupported behavior of community surrounding which establish unideal streetscape condition i.e. littering waste to the river, congestion created from street vendors and unintended gathering place on the sidewalks. Therefore, this study aims to determine the appropriate arrangement for streetscape with focusing on plantations arrangement. Method used in this study was field survey by implementing observations, field measurements and documentations data collection technique. Data were analyzed with descriptive qualitative method by comparing streetscape suitability with regulation standards and literatures. Results were indicated that the streetscape has potency to develop by arranging the plantations. It can be achieved by following government regulation on standard of streescape. Based on current situation of the street, it found that the previous plan for tree selection were not ideal, so it need to adjust by selecting and planting quen crape myrtle trees (Lagerstroemia speciosa) to substitute the previous streetscape plantations plan. Then, this recommended species was used as the main concept for structuring streetscape plantation at the downstream of Tukad Mati. The concept for spatial arrangement with this new tress selection will providing comfortable space for the user and improving the quality of the physical and visual of the street.
\end{abstract}

Keywords: landscape plan, plant arrangement, streetscape plantation selection, Tukad Mati.

\section{Pendahuluan}

Kelurahan Legian terletak di wilayah Kecamatan Kuta, Kabupaten Badung. Daerah legian merupakan termasuk Kawasan pariwisata strategis di kabupate badung. Pekermbangan pariwisata di daerah legian sangat dipengaruhi oleh adanya aksesibilitas yang aman dan nyaman. Selama ini banjir sering terjadi di bagian hilir Tukad Mati, Legian karena tidak dapat menampung debit air hujan sehingga meluap dan menggenangi wilayah sekitar termasuk jalan di bagian hilir Tukad Mati, Legian. Oleh karena itu adanya upaya memperhatikan lanskap jalan terutama lanskap jalan di bagian hilir Tukad Mati, Legian, Kuta, Badung. Lanskap jalan yang dimaksud adalah Jalan Eka Laweya, Jalan Sri Rama, dan Jalan Kresna yang terletak di sepanjang bagian hilir Tukad Mati, Legian, Kuta, Badung. Saat ini kondisi jalan di kawasan tersebut sering mengalami banjir yang diakibatkan oleh karena Tukad Mati tidak dapat menampung debit air hujan (BWS, 2019) sehingga menggenangi wilayah sekitarnya termasuk jalan di sekitar hilir Tukad Mati, Legian, Kuta, Badung. Oleh karena itu, pemerintah setempat berupaya membangun prasarana pengendalian banjir di sekitar hilir Tukad Mati, Legian, Kuta, Badung. Selain itu, dilakukan pula usaha penataan tanaman lanskap jalan pada kawasan ini. Penataan tanaman lanskap jalan yang dimaksud yaitu menanam tanaman tabebuya (Tabebuia sp.). Tujuan dari pemilihan tanaman dan penataan yang direncanakan adalah untuk memberikan kenyamanan bagi pengguna jalan serta meningkatkan kualitas lingkungan fisik dan visual. Oleh karena itu, penelitian ini bertujuan untuk mengetahui penataan tanaman perindang di sepanjang jalan yang sesuai di bagian hilir Tukad Mati, Legian, Badung. Penataan yang dihasilkan diharapkan memberi kontribusi bagi penataan tanaman lanskap jalan di bagian hilir Tukad Mati, Legian, Kuta, Badung baik bagi pemerintah setempat maupun pihak pengelola. 
2. Metode

\subsection{Lokasi dan Waktu Penelitian}

Penelitian ini berlokasi di bagian hilir Tukad Mati, Kelurahan Legian, Kecamatan Kuta, Kabupaten Badung, Provinsi Bali. (Gambar 1). Penelitian berlangsung selama 8 bulan, dimulai dari bulan Juni 2019 hingga Februari 2020

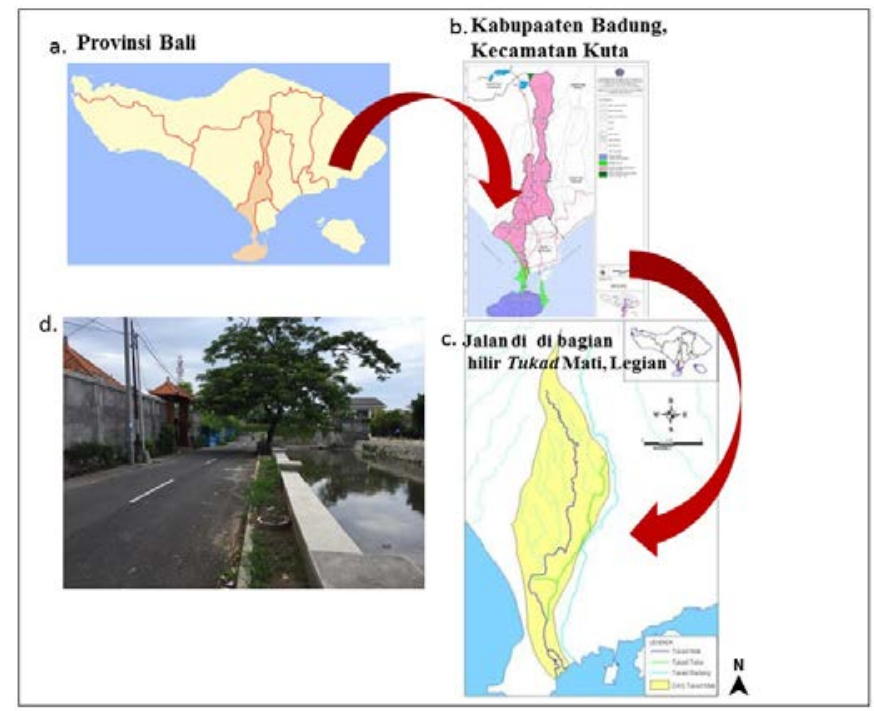

Gambar 1. Lokasi Penelitian

(a. Peta Provinsi Bali b. Peta Kabupaten Badung c. Peta Tukad Mati d. Bagian Jalan Di Bagian Hilir Tukad Mati) (Google Earth dan Observasi, 2019)

\subsection{Alat dan Bahan}

Alat dan bahan yang digunakan dalam penelitian yaitu kamera, laptop dengan software Auto CAD 2010, Google Earth, Adobe Photoshop CS6, Microsoft Word 2010, dan Microsoft Excel 2010.

\subsection{Metode Penelitian}

Metode penelitian yang digunakan adalah metode survei. Jenis data yang dikumpulkan dalam penelitian yaitu kondisi eksisting meliputi data biofisik dan sosial. Data biofisik meliputi data curah hujan, vegetasi, satwa, hidrologi, tanah, karakteristik jalan, dan visual. Sedangkan data sosial berupa perilaku masyarakat dan pengguna di tempat penelitian.

\subsection{Metode Pengumpulan Data}

Data yang dikumpulkan merupakan data primer dan juga merupakan data sekunder. Metode pengumpulannya untuk data primer dilakukan observasi langsung di tapak, pengukuran dengan meteran dan dokumentasi. Data sekunder didapat melalui undang-undang dan literatur yang menjadi acuan untuk penataan tanaman lanskap jalan di bagian hilir Tukad Mati, Legian, Kuta, Badung.

\subsection{Metode Analisis Data dan Tahapan Penelitian}

Metode analisis data dilakukan secara deskriptif kualitatif dengan menjelaskan secara faktual kondisikondisi yang ada di lapangan dan membandingkan kesesuaiannya dengan standar dalam undang-undang dan literature dalam penataan lanskap jalan yang menjadi acuan untuk penataan lanskap jalan. Tahapan penelitian dimulai dari inventarisasi di bagian hilir Tukad Mati, Legian, Kuta, Badung untuk mencari data tentang kondisi biofisik, sosial, dan kondisi umum tapak. Hasil inventarisasi kemudian dianalisis untuk menemukan potensi, kendala, dan kesesuaian tapak untuk penataan tanaman lanskap jalan. Hasil analisis digunakan sebagai dasar konsep pengembangan penataan. Konsep yang sudah dikembangkan digunakan sebagai konsep 
perencanaan penataan dengan hasil berupa pembagian zona penataan dan desain penataan kawasan lanskap jalan. Berikut bagan tahapan penelitian yang dilakukan (Gambar 2).

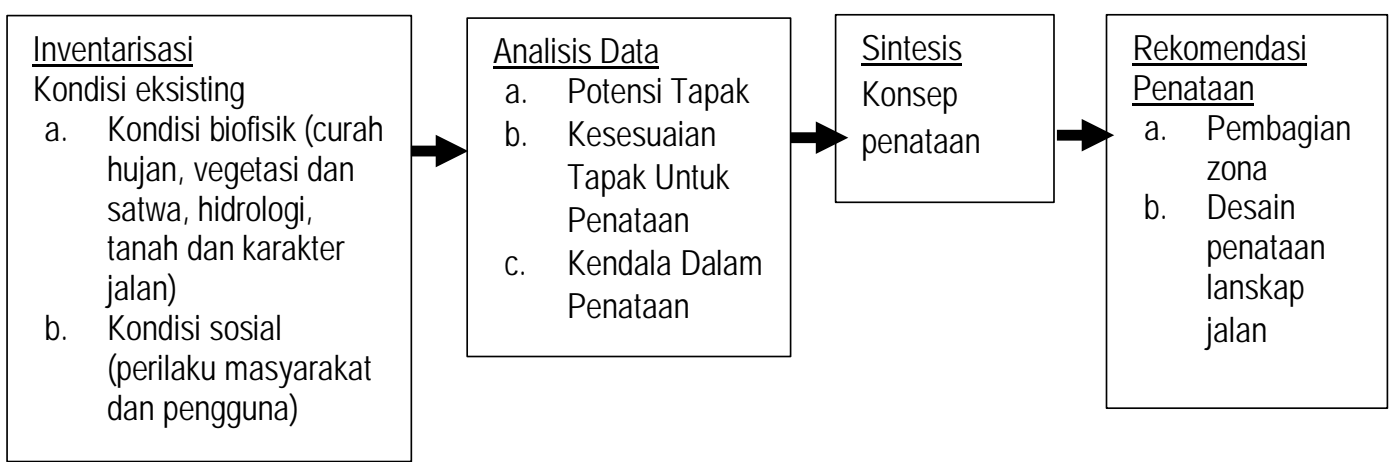

Gambar 2. Tahapan Penelitian (Gold (1980) dengan penyesuaian)

\subsection{Batasan Penelitian}

Lokasi penelitian dari Jalan Eka Laweya, Jalan Sri Rama sampai Jalan Kresna, Desa Legian, Kecamatan Kuta, Kabupaten Badung di bagian hilir Tukad Mati, dengan panjang jalan $3,5 \mathrm{~km}$, lebar jalan $5 \mathrm{~m}$, dan lebar tepi jalan 0,8 $\mathrm{m}$ sampai dengan $1 \mathrm{~m}$. Hasil akhir berupa rekomendasi penataan tanaman lanskap jalan di bagian hilir Tukad Mati, Legian, Kuta.

\section{Hasil dan Pembahasan}

\subsection{Gambaran Umum Wilayah Legian}

Legian merupakan kelurahan yang terletak di wilayah Kecamatan Kuta, Kabupaten Badung, dengan luas wilayah 3,05 km². Jarak dari pusat Kota Mangupura sejauh $12 \mathrm{~km}$ (BPS, 2019). Legian memiliki batas wilayah, bagian utara Legian berbatasan dengan Kelurahan Seminyak, bagian timur Legian berbatasan dengan Kota Denpasar dan Kelurahan Kuta, bagian selatan Legian berbatasan dengan Kelurahan Kuta dan bagian barat Legian berbatasan dengan Samudera Indonesia.

\subsection{Kondisi Biofisik}

\subsubsection{Iklim, Hidrologi dan Tanah}

Legian memiliki iklim tropis, dengan curah hujan yang turun rata-rata 1000- $2000 \mathrm{~mm}$ pada tahun 2014 sampai dengan 2019. Suhu udara rata-rata minimum $30^{\circ} \mathrm{C}$ dan maksimum $34^{\circ} \mathrm{C}$ (Badan Metereologi, Klimatologi, 2019).Legian memiliki karakteristik hidrologi yang meliputi sungai dan air tanah. Tukad Mati secara administrasi melintasi Kabupaten Badung dan Kota Denpasar Kecamatan Mengwi, Kecamatan Kuta dan Kecamatan Denpasar Barat. Air Tukad Mati digunakan untuk mengairi beberapa lahan sawah dan sebagai drainase kota (Kementerian PUPR Direktorat Jenderal Sumber Daya Air Balai Wilayah Sungai Balii Penida, 2019). Menurut data hidrogeologi Bali di Kabupaten Badung, pengelompokan kandungan air tanah di Kabupaten Badung, wilayah Kuta, Kuta Utara hingga sebagian Kecamatan Mengwi kandungan air tanahnya sebanyak $10 \mathrm{lt} / \mathrm{det}$.

Jenis tanah di sekitar muara sungai dan beberapa daerah pesisir Kuta yaitu alluvial. Tanah alluvial merupakan endapan pantai yang tersusun dari pasir.

\subsubsection{Vegetasi dan satwa}

Beberapa vegetasi yang terletak di Jalan Eka Laweya, Jalan Sri Rama, dan Jalan Kresna di bagian hilir Tukad Mati, Legian, Kuta, Badung seperti glodokan tiang (Polyalthia longifolia), waru (Hibiscus tiliaceus), tanjung (Mimusops elengi), kerai payung (Filicium decipiens), kelapa (Cocos nucifera L.), asam jawa (Tamarindus indica) dan kamboja (Plumeria sp.). Selain vegetasi, terdapat juga berbagai satwa seperti burung, tupai, dan ikan air tawar. 


\subsubsection{Karakteristik Jalan Eka Laweya, Jalan Sri Rama, dan Jalan Kresna}

Panjang Jalan Eka Laweya 0,5 km, lebar jalan $5 \mathrm{~m}$, serta lebar sempadan jalan 0,8 $\mathrm{m}$. Panjang Jalan Sri Rama 1,8 km, lebar jalan $5 \mathrm{~m}$, serta lebar sempadan jalan 0,8 $\mathrm{m}$ dan panjang Jalan Kresna 1,2 km, lebar jalan $5 \mathrm{~m}$ serta lebar sempadan jalan berkisar $0,8 \mathrm{~m}$ hingga $1 \mathrm{~m}$.

Berdasarkan fungsinya Jalan Eka Laweya, Jalan Sri, dan Jalan Kresna, Legian, Badung merupakan jalan lokal yang melayani angkutan lokal setempat dengan tujuan perjalanan jarak dekat. Kecepatan rata- rata rendah dan jalan masuk tidak dibatasi

Berdasarkan statusnya Jalan Eka Laweya, Jalan Sri Rama, dan Jalan Kresna, Legian, Badung merupakan jalan kabupaten yang menghubungkan Kota Denpasar dengan Legian sebagai pusat kegiatan lokal. Jalan kabupaten juga merupakan jalan lokal untuk alternatif jalan nasional dan provinsi.

Berdasarkan kelasnya Jalan Eka Laweya, Jalan Sri Rama, dan Jalan Kresna, Legian, Badung merupakan Jalan kelas III, yaitu jalan lokal yang dapat dilalui kendaraan bermotor dengan ukuran lebar tidak melebihi 2,1 m, ukuran panjang tidak melebihi $9 \mathrm{~m}$, dan muatan sumbu terberat 8 ton.

Jalan Eka Laweya, Jalan Sri Rama, dan Jalan Kresna, Legian, dimanfaatkan sebagai akses alternatif menuju lokasi wisata daerah Legian, Kuta. Selain itu jalan ini dimanfaatkan untuk akses menuju ke Bandar Udara I Gusti Ngurah Rai. Sepanjang jalan ini terdapat tanaman eksisting dengan jarak tanam 3 sampai 5 meter di setiap jalan.

\subsection{Kondisi Sosial}

Menurut informasi kependudukan di Kelurahan Legian tahun 2016, terdapat 4.208 jiwa. Masyarakat yang tinggal di bagian hilir Tukad Mati, Legian merupakan masyarakat lokal dan pendatang, baik dari luar Kabupaten Badung maupun dari luar Bali, sehingga keragaman masyarakat di wilayah tersebut cukup beragam.

Hasil dari observasi lapangan yaitu aktivitas masyarakat di sepanjang Jalan Eka Laweya, Jalan Sri Rama, dan Jalan Kresna, Legian yaitu kegiatan rekreasi seperti memancing dan aktivitas ekonomi seperti berjualan di tepi jalan. Banyak juga pengendara transportasi dalam jaringan (daring) yang berhenti dan berkumpul di tepi jalan pada bagian hilir Tukad Mati Legian untuk sekedar menunggu pesanan dalam jaringan (daring) namun dengan kondisi tidak ada fasilitas parkir dan tempat untuk duduk. Kondisi ini dapat membahayakan pengguna jalan karena terbatasnya area bahu jalan dan tidak adanya pembatas atau pagar antara jalan serta mengurangi keindahan visual di bagian hilir Tukad Mati, Legian, Kuta, Badung. Oleh karena itu perlu adanya penataan tanaman lanskap jalan di Jalan Eka Laweya, Jalan Sri Rama, dan Jalan Kresna, Legian, Badung di bagian hilir Tukad Mati, Legian untuk menciptakan kenyamanan bagi pengguna jalan serta meningkatkan kualitas lingkungan fisik dan visual.

\subsection{Analisis}

Pembagian segmen pada ruas jalan di bagian hilir Tukad Mati, Legian, Kuta, Badung untuk mempermudah penataan kawasan. Segmen 1 berwarna merah merupakan Jalan Eka Laweya, segmen 2 berwarna biru merupakan Jalan Sri Rama, dan segmen 3 berwarna kuning merupakan Jalan Kresna (Gambar 3). 


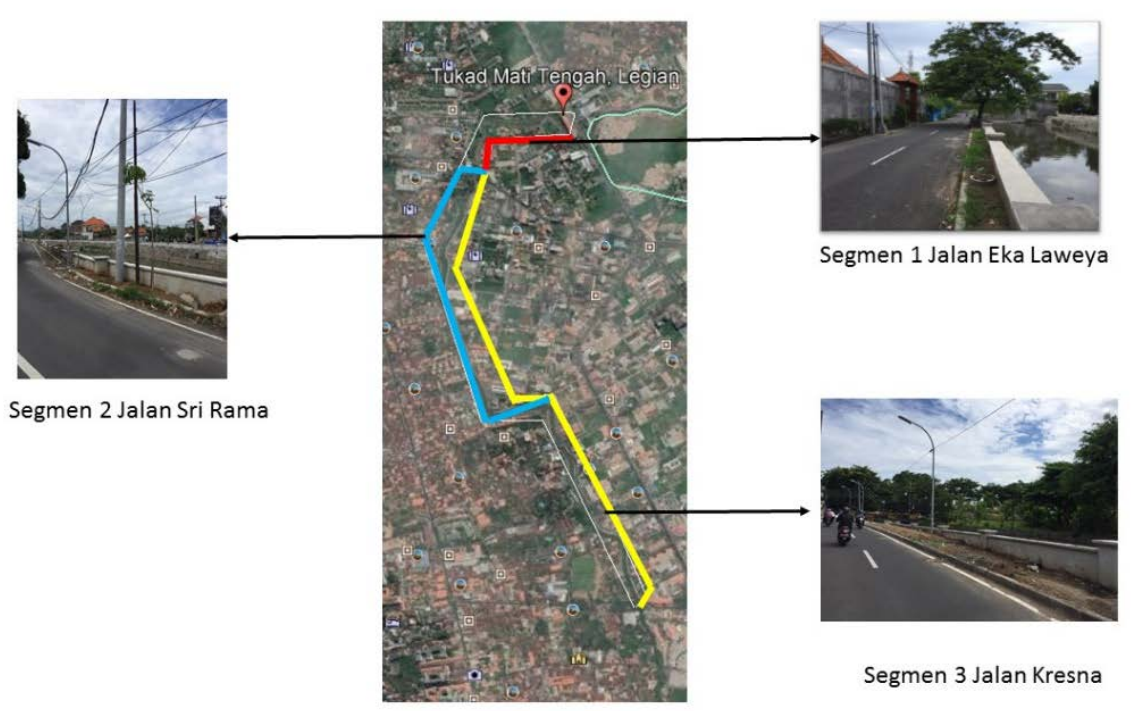

Gambar 3. Pembagian Segmen Jalan di Bagian Hilir Tukad Mati, Legian, Kuta, Badung (Observasi dan Google Earth, 2020)

\subsubsection{Analisis potensi dalam penataan tanaman lanskap jalan}

Analisis potensi pada jalan di bagian hilir Tukad Mati, Legian, Kuta, Badung untuk pengembangan penataan tanaman lanskap jalan yaitu ketiga segmen ini memiliki potensi untuk menjadi akses yang memenuhi fungsi keamanan, nyaman, dan menarik visual untuk pengguna jalan sesuai dengan tujuan lanskap jalan. (Departemen Pekerja Umum Direktorat Jendral Bina Marga, 1996)Tanaman eksisting yang dipertahankan yaitu tanaman kerai payung (Filicium decipiens). Pemilihan jenis tanaman keira payung (Filicium decipiens) karena memiliki karakteristik seperti percabangan $2 \mathrm{~m}$ di atas tanah, bentuk percabangan batang tidak merunduk, bermassa daun padat, ditanam secara berbaris, dan tidak mudah tumbang karena tumbuh di tepi sungai.(Departemen Pekerja Umum Direktorat Jenderal Bina Marga, 1996)

3.4.2 Analisis kendala dalam penataan tanaman lanskap jalan

Analisis kendala dalam penataan lanskap jalan di bagian hilir Tukad Mati, Legian, Kuta, Badung untuk pengembangan penataan lanskap jalan yaitu Menurut Badrunasar \& Nurahmah, 2012 karakteristik dari tanaman eksisting glodokan tiang (Polyalthia longifolia), waru (Hibiscus tiliaceus), tanjung (Mimusops elengi), asam jawa (Tamarindus indica) dapat merusak konstruksi jalan karena tanaman ini pertumbuhannya cepat, serta daun yang mudah rontok sehingga mengganggu pengguna jalan. Kelapa (Cocos nucifera L.) dan kamboja (Plumeria sp.) tidak termasuk tanaman lanskap jalan, sehingga tanaman tersebut kurang baik dijadikan vegetasi pada lanskap jalan di bagian hilir Tukad Mati, Legian, Kuta, Badung (Menteri Pekerjaan Umum, 2012). Jarak tanam tanaman minimum sembilan meter dari tepi perkerasan untuk daerah luar perkotaan dan 4 meter untuk daerah perkotaan, dan harus dipelihara untuk jalan yang berdekatan dengan utilitas umum. Jarak tanaman dari tepi perkerasan tidak teratur dan tidak sesuai yaitu empat meter (Menteri Pekerjaan Umum, 2012). Perdu, semak, dan pohon dapat ditanam sepanjang pedestrian pada sisi jalan yang jauh dari jalur lalu lintas (Menteri Pekerjaan Umum, 2012). Berdasarkan hasil dari observasi pohon yang ditanam di sepanjang segmen satu sampai dengan tiga sangat berdekatan dengan jalur lalu lintas karena sisi jalan yang tidak luas. Aktivitas masyarakat sangat mempengaruhi kualitas fisik lanskap jalan yang berdampingan dengan sungai. Berdasarkan hasil dari observasi kebanyakan masyarakat yang tinggal berdekatan dengan Tukad Mati Legian bagian hilir memiliki perilaku membuang sampah sembarangan, pedagang kaki lima banyak yang berjualan di tepi jalan, pengendara transportasi dalam jaringan (daring) banyak parkir sembarangan di tepi jalan hingga membuat tempat berkumpul di bahu jalan. Aktivitas masyarakat tersebut menimbulkan dampak seperti sampah yang berserakan, dan mengurangi keindahan visual di bagian hilir Tukad Mati, Legian, Kuta, Badung. 


\subsection{Konsep Penataan}

Berdasarkan perencanaan yang sudah dijalankan oleh Pemenrintah Kabupaten Badung, tanaman tabebuya (Tabebuia sp.) menjadi vegetasi dominan di lanskap jalan di bagian hilir Tukad Mati, Legian, Kuta, Badung (Gambar 4).

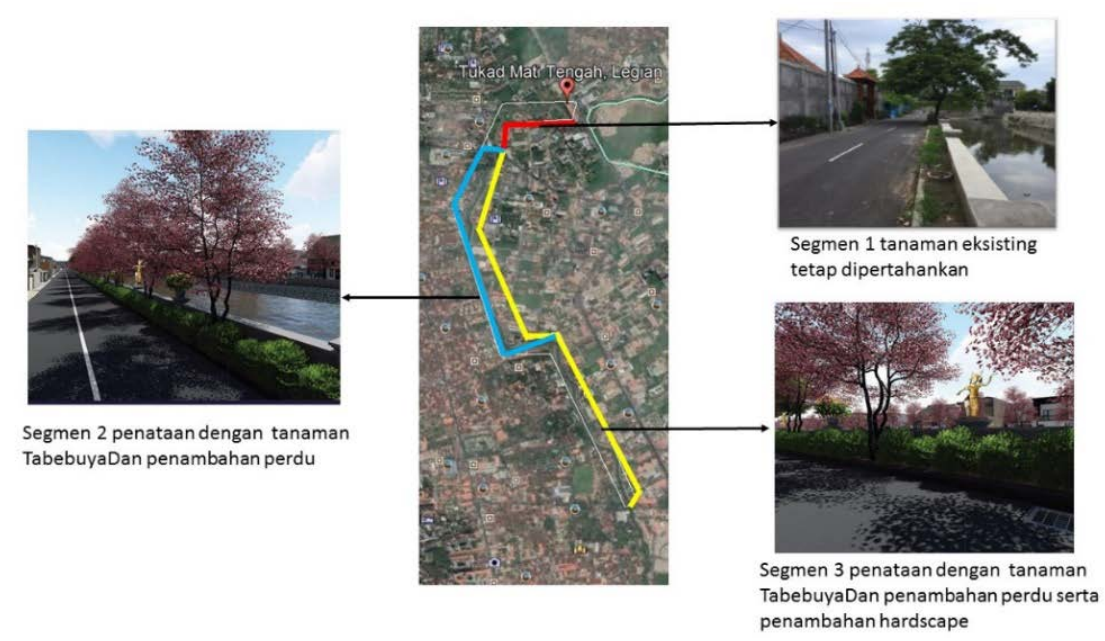

Gambar 4. Ilustrasi Perencanaan Lanskap Jalan Setiap Segmen dengan Penambahan Tabebuya (Tabebuia sp.) (Observasi dan Google Earth, 2020)

Berdasarkan Menteri Pekerjaan Umum, 2012 tanaman tabebuya (Tabebuia sp.) tidak termasuk dalam daftar tanaman yang direkomendasikan ditanam pada jaringan jalan. Selain itu, tabebuya (Tabebuia sp.) memiliki karakteristik perakaran merusak konstruksi jalan, sulit dalam perawatan, batang atau percabangan mudah patah, dan daun tidak mudah rontok atau gugur.

\subsection{Rekomendasi Penataan}

Bungur (Lagerstroemia speciosa) dijadikan tanaman lanskap jalan karena memiliki karakteristik yaitu perakaran tanaman ini kuat, tanaman ini juga membutuhkan cahaya matahari penuh dan pertumbuhannya terganggu jika ditanam di tempat teduh, dapat hidup di kondisi tanah yang subur dengan drainase yang baik agar tumbuh dengan baik. Tanaman ini tahan terhadap kondisi kekeringan. Pada musim kemarau tanaman bungur menggugurkan daunnya, bunga-bunga biasanya muncul bersamaan dengan munculnya daun-daun baru. Tanaman bungur banyak ditanam di pinggir jalan kota-kota di Indonesia. Penataan tanaman bungur ini dapat meningkatkan kualitas fungsional lingkungan, dapat menjadi kontrol visual seperti pembatas pandangan karena penataan lanskap ini berada di bagian hilir Tukad Mati, Legian, Kuta, Badung serta dapat mengurangi paparan cahaya matahari dan cahaya lampu jalan. Penempatan tanaman bungur dibagi menjadi 3 segmen seperti pada Gambar 5. Pada segmen satu (Jalan Eka Laweya) dan segmen tiga (Jalan Kresna) ditanami tanaman bungur dan mempetahankan tanaman eksisting kerai payung. Penataan tanaman lanskap jalan pada segmen dua (Jalan Sri Rama) menggunakan tanaman bungur sepenuhnya. Selain itu adapun penambahan semak yaitu bugenvil (Bougainvillea) yang bertujuan untuk mengurangi masyarakat yang membuang sampah sembarangan, mengurangi aktivitas masyarakat di bahu jalan, dan mengurangi pengendara yang parkir di bahu jalan. 


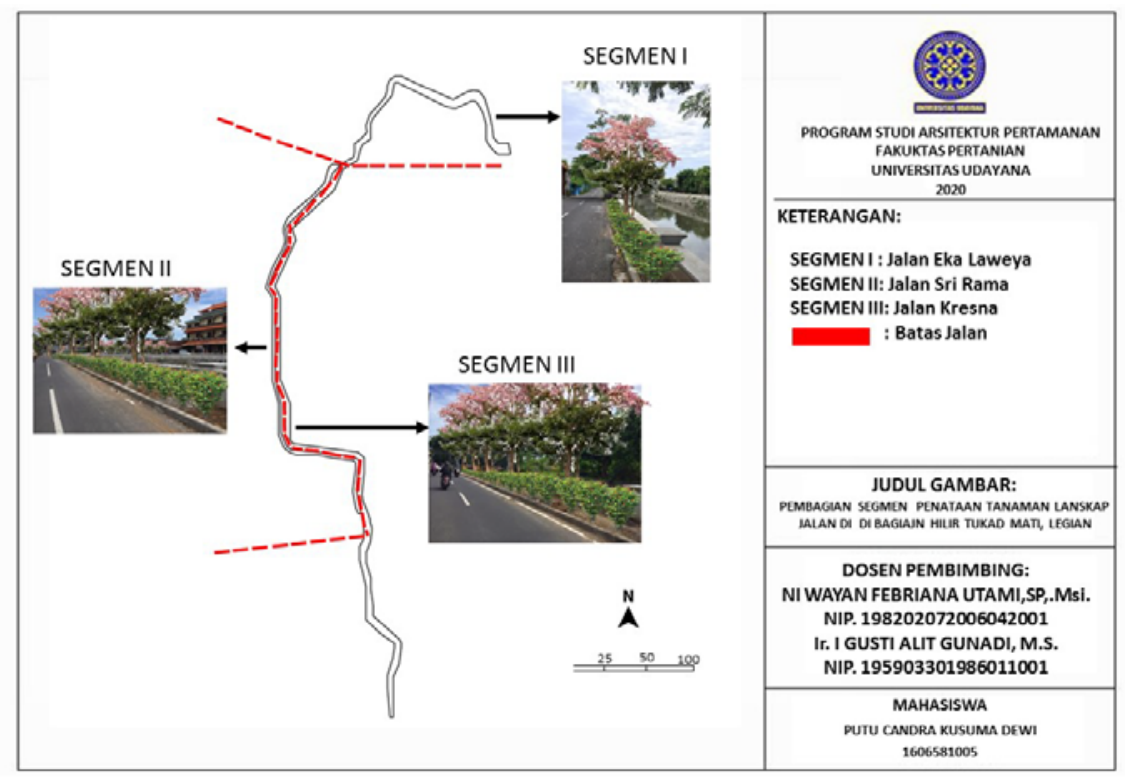

Gambar 5. Penataan Tanaman Lanskap Jalan di Bagian Hilir Tukad Mati, Legian, Kuta, Badung dengan Pohon Bungur (Lagerstroemia speciosa)

\subsubsection{Desain Penataan Tanaman Lanskap Jalan}

Pada Gambar 6 menunjukkan tampak atas penataan tanaman lanskap jalan di bagian hilir Tukad Mati, Legian, Kuta, Badung. Pada Jalan Eka Laweya peletakan pohon bungur sebanyak 100 tanaman dengan jarak tanam lima $\mathrm{m}$. Jalan Sri Rama peletakan pohon bungur sebanyak 360 tanaman dengan jarak tanam lima meter. Jalan Kresna sebanyak 240 tanaman dengan jarak tanam 5 m.Tanaman kerai payung menjadi tanaman eksisiting yang dipertahankan karena tanaman tersebut cukup besar dan kerai payung tersebar di Jalan Eka Laweya dan Jalan Kresna.

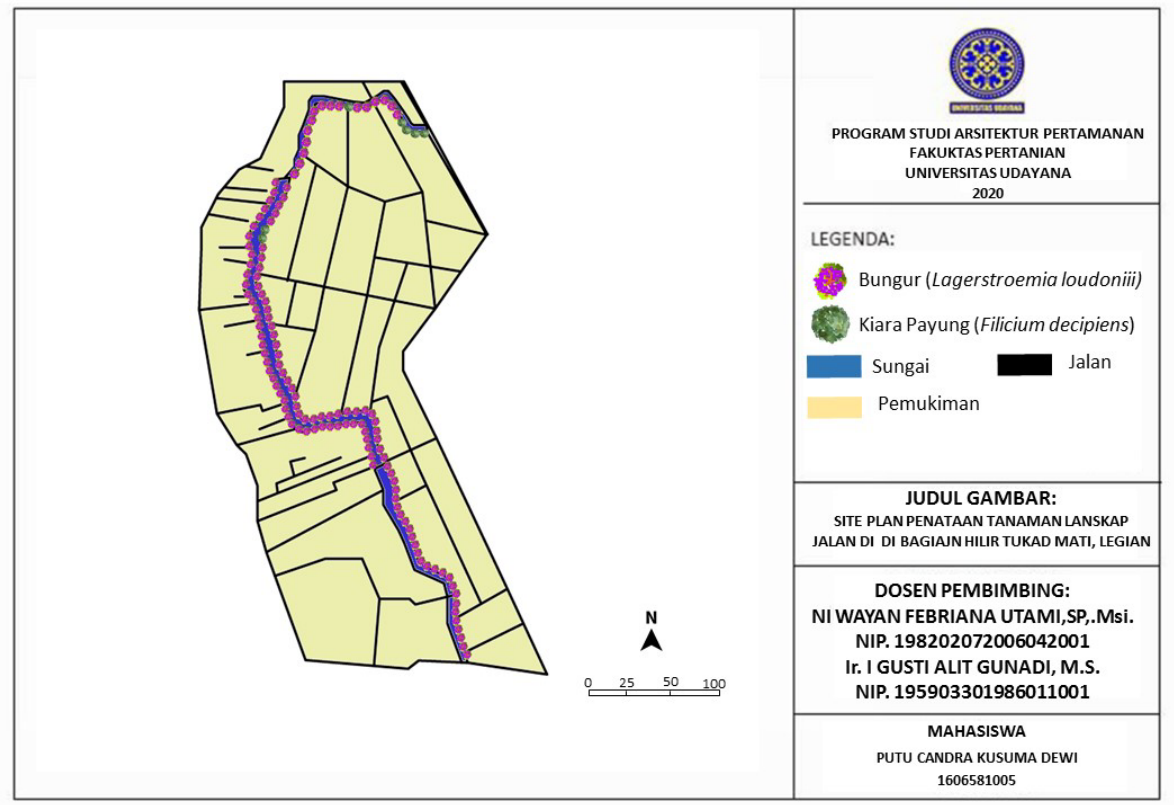

Gambar 6. Site Plan Penataan Tanaman Lanskap Jalan di Bagian hilir Tukad Mati, Legian, Kuta, Badung

Pada Gambar 7 menunjukkan tampak depan penataan tanaman lanskap jalan di bagian hilir Tukad Mati, Legian, Kuta, Badung. Pohon bungur diletakkan di tepi jalan dengan lebar sempadan jalan 0,8 $\mathrm{m}$ sampai dengan satu meter. Pada Gambar 8 menunjukkan gambar pembagian segmen dengan gambar tampak depan 
penataan tanaman lanskap jalan di bagian hilir Tukad Mati, Legian, Kuta, Badung. Pohon bungur diletakkan di tepi jalan dengan lebar sempadan jalan 0,8 $\mathrm{m}$ sampai dengan satu $\mathrm{m}$.

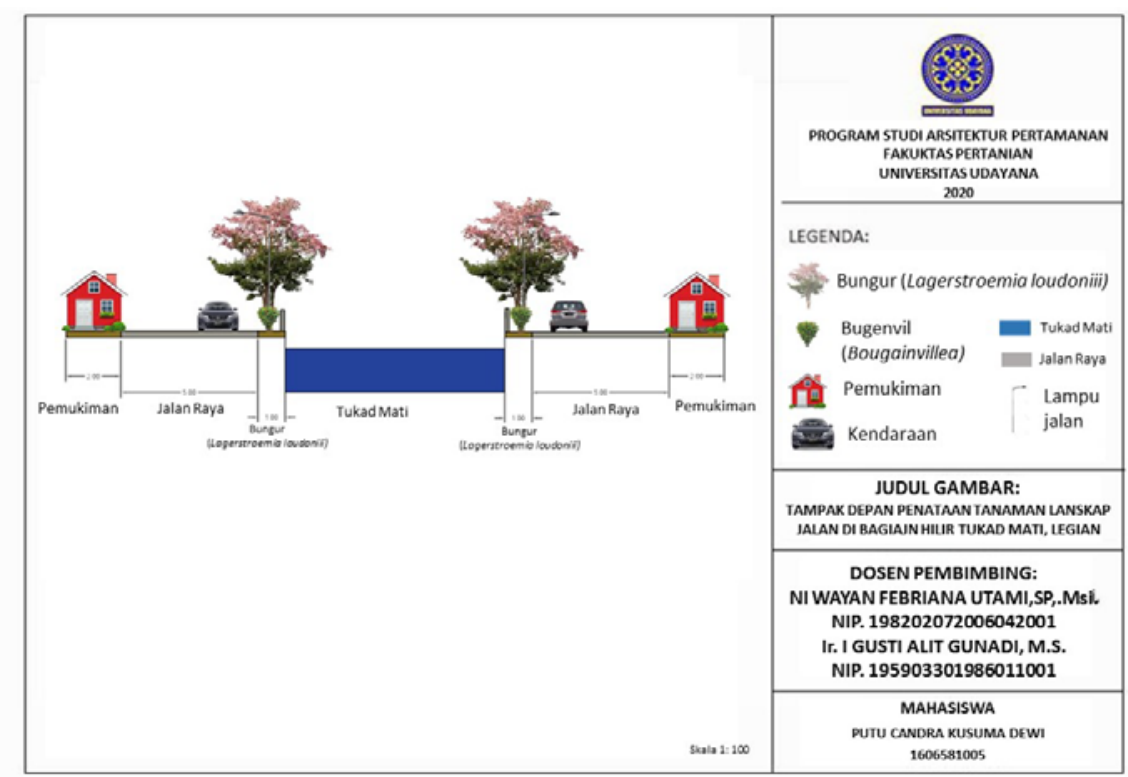

Gambar 7. Tampak Depan Penataan Tanaman Lanskap Jalan di Bagian Hilir Tukad Mati, Legian, Kuta, Badung

Pada Gambar 8 menunjukkan tampak atas segmen 1 (Jalan Eka Laweya), segmen 2 (Jalan Sri Rama), dan segmen 3 (Jalan Kresna) ditanami tanaman bungur dan mempetahankan tanaman eksisting kerai payung.

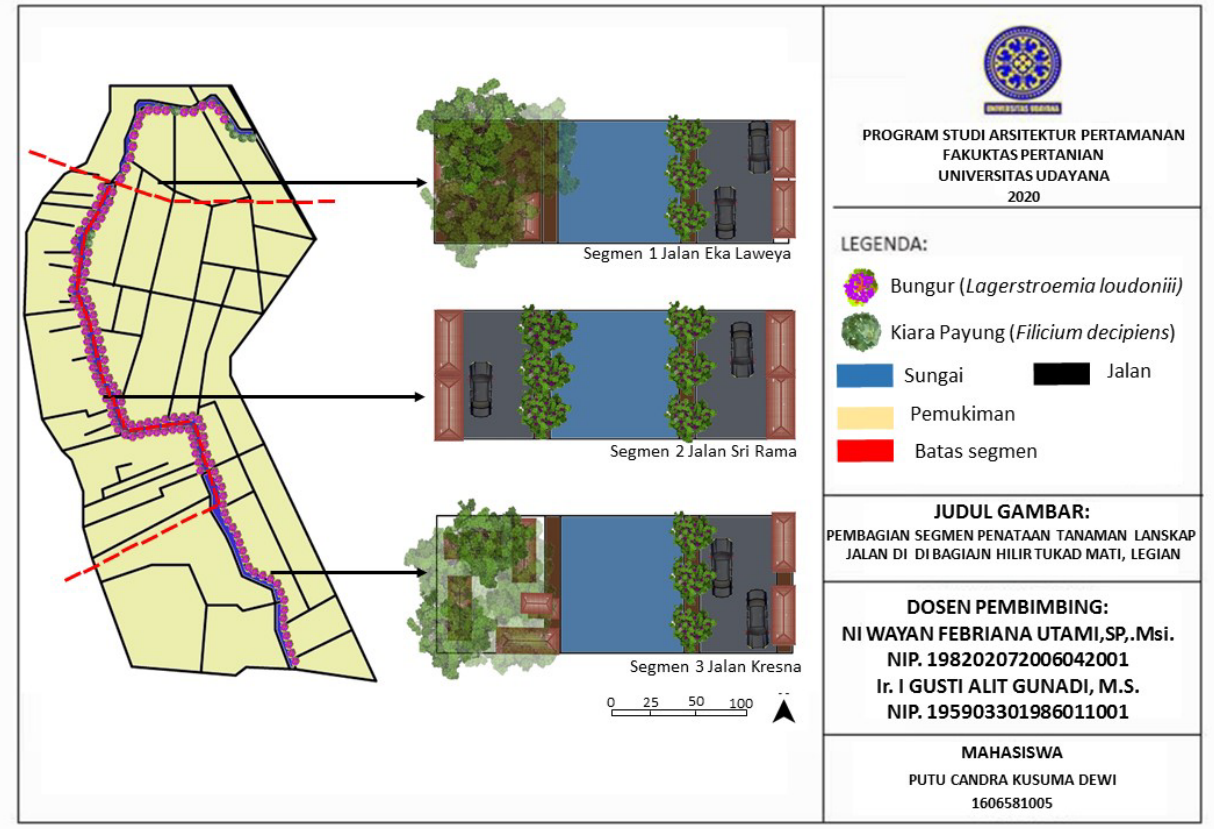

Gambar 8. Pembagian Segmen Penataan Tanaman Lanskap Jalan di Bagian Hilir Tukad Mati, Legian, Kuta, Badung

\section{Simpulan dan Saran}

\subsection{Simpulan}

Jalan di bagian hilir Tukad Mati, Legian, Kuta, Badung untuk pengembangan penataan tanaman lanskap jalan memiliki potensi untuk menjadi akses yang memenuhi fungsi keamanan, nyaman, dan menarik visual untuk pengguna jalan. Penggunaan tanaman tabebuya (Tabebuia sp.) Pada penataan tanaman lanskap 
jalan di bagian hilir Tukad Mati, Legian, Kuta, Badung yang di rencanakan sebelumnya kurang sesuai terhadap kondisi jalan karena tabebuya tidak termasuk tanaman perindang dan kurang baik untuk tanaman lanskap jalan karena pertumbuhannya yang cepat sehingga konstruksi jalan cepat rusak. Oleh karena itu, digantikan dengan tanaman bungur (Lagerstroemia speciosa), penataan tanaman bungur ini dapat meningkatkan kualitas fungsional lingkungan, dapat menjadi kontrol visual seperti pembatas pandangan karena penataan lanskap ini berada di bagian hilir Tukad Mati, Legian, Kuta, Badung serta dapat mengurangi paparan cahaya matahari dan cahaya lampu jalan. Rekomendasi yang diberikan berupa ha konsep desain penataan tanaman lanskap jalan di sepanjang jalan di bagian hilir Tukad Mati, Legian, Kuta, Badung.

\subsection{Saran}

Penataan tanaman yang dihasilkan dapat menjadi rekomendasi penataan tanaman lanskap jalan di bagian hilir Tukad Mati, Legian, Kuta, Badung bagi Pemerintah Daerah Kabupaten Badung dan pihak pengelola agar memberikan kenyamanan bagi pengguna jalan serta meningkatkan kualitas lingkungan fisik dan visual. Perlu kegiatan perencanaan dan desain yang lebih spesifik untuk tapak.

\section{Daftar Pustaka}

Badan Metereologi, Klimatologi. 2019. Data Curah Hujan Kecamatan Kuta 2014 sampai 2019. Available online at: https://www.bmkg.go.id/ (diakses pada 10 Februari 2020).

Badrunasar, A., \& Y. Nurahmah. 2012. Pertelaan Jenis Pohon Koleksi Arboretum. Balai Penelitian Teknologi Agroforestry. Jawa Barat.

Badan Pusat Statistik Kabupaten Badung. 2019. Penduduk Menurut Kecamatan di Kabupaten Badung $2010-$ 2019. Available online at: https://badungkab.bps.go.id/ (diakses pada 10 Februari 2020).

Departemen Pekerja Umum Direktorat Jendral Bina Marga. 1996. Tata Cara Perencanaan Teknik Lanskap Jalan No: 033/T/BM/1996.

Gold, S. 1980. Recreation Planning and Design. McGraw-Hill Book Company, New York.

Kementrian PUPR Direktorat Jendral Sumber Daya Air Balai Wilayah Sungai Bali Penida. 2019. Data Profil

DAS Tukad Mati Bali. Available online at:http://sda.pu.go.id/pages/balai_detail/19/Bali-Penida (diakses pada 5 Desember 2019).

Menteri Pekerjaan Umum. 2012. Peraturan Menteri Pekerja Umum Nomor: 05/PRT/M/2012 Tentang Pedoman penanaman pohon pada sistem jaringan jalan. 